\title{
5-Aminosalicylic Acid Chemoprevention in Inflammatory Bowel Diseases: Is It Necessary in the Age of Biologics and Small Molecules?
}

\author{
Hans Herfarth ${ }^{a}$ Stephan R. Vavrickab \\ aDivision of Gastroenterology and Hepatology, University of North Carolina, Chapel Hill, NC, USA; bentrum für \\ Gastroenterologie und Hepatologie AG, Zürich, Switzerland
}

\section{Keywords}

Inflammatory bowel disease - Chemoprevention .

Ulcerative colitis · 5 -Aminosalicylic acid $\cdot$ Colorectal cancer

\begin{abstract}
Background: Due to the increased incidence of colorectal cancer in inflammatory bowel diseases (IBDs), the value of chemoprevention for this patient group has been repeatedly debated in the past decade. This review describes available evidence and the current recommendations for chemoprevention in national and international guidelines IBD guidelines. Summary: 5-Aminosalicylic acid (5-ASA) compounds are the preferred therapeutic option for mild to moderate ulcerative colitis (UC). Aside from the known antiinflammatory effects, their chemopreventive abilities have been described in vitro and in vivo. Pooling the increasing number of retrospective and population-based clinical studies over the last 15 years, 7 consecutive meta-analyses revealed partially conflicting results for the chemopreventive efficacy of 5-ASA, and thus, not all IBD guidelines currently recommend chemoprevention with mesalamine compounds. Accumulating evidence for decreasing the colorectal cancer (CRC) risk in support of thiopurines more recently shows a protective effect. This effect seems solely mediated
\end{abstract}

by control of intestinal inflammation since, for this drug class, another mechanistic interference in IBD-associated CRC pathogenesis is not known. The results regarding chemopreventive efficacy for ursodeoxycholic acid or folic acid are equivocal, and the use of these medications to prevent CRC is not firmly established. Like UC, the risk of CRC is also significantly increased in patients with Crohn's disease (CD), especially Crohn's colitis. However, no published studies exclusively assess the effects of surveillance on the early detection of cancer or CRC chemoprevention in CD patients. In meta-analyses, which predominantly included UC patients, 5-ASA or thiopurines were not beneficial in small CD subgroups. The level of evidence for anti-TNFa agents, anti-integrin (e.g., vedolizumab), or anti-IL-12/IL-23 agents (e.g., ustekinumab) and Janus kinase inhibitors is currently too low or nonexistent to use them solely for chemoprevention in UC or CD patients. Key Message: Intestinal inflammation is one of the main risk factors for developing CRC in IBD, and all drugs that induce and maintain mucosal healing most likely also decrease the IBD-associated CRC risk. Thus, a therapeutic strategy of adding a 5-ASA therapy to a successfully mucosal healing-inducing therapy, for example, with a biologic or a small molecule merely to prevent CRC appears to be obsolete.

(c) 2021 The Author(s)

Published by S. Karger AG, Basel
C 2021 The Author(s).

Published by S. Karger AG, Basel

This is an Open Access article licensed under the Creative Commons Attribution-NonCommercial-4.0 International License (CC BY-NC) (http://www.karger.com/Services/OpenAccessLicense), applicable to the online version of the article only. Usage and distribution for commercial purposes requires written permission.
Correspondence to:

Hans Herfarth, hherf@med.unc.edu 


\section{Introduction}

The increased colorectal cancer (CRC) risk in patients with ulcerative colitis (UC) became apparent in the second half of the previous century. Eaden et al. [1] reported a CRC prevalence of $3.7 \%$ based on a meta-analysis, including 54,478 patients of 116 studies between 1966 and 1999. The CRC risk increased over time to cumulative probabilities to develop CRC of $2 \%$ by 10 years, $8 \%$ by 20 years, and $18 \%$ by 30 years. However, in the last 20 years, several epidemiologically well-performed studies, including a meta-analysis by Jess et al. [2], have shown a decreasing or lower CRC risk with estimations $<1 \%$ at 10 years and from 1.1 to $5.3 \%$ at 20 years. A recently published large population-based study including 96,000 individuals with UC from Denmark and Sweden by Olen et al. [3] found a 1.7-fold increased risk for incident CRC and a 1.6-fold increased risk of death from CRC for a patient with UC. Based on this study, the incident CRC or death from CRC has been decreasing since the early 2000s, corresponding to 1 additional case of incident CRC per 1,058 UC patients and 1 additional death from CRC per 3,041 UC patients during the last 5 years of follow-up [3].

Patients with Crohn's disease (CD) are also at increased risk for developing CRC. In a meta-analysis of population-based studies in CD, Jess et al. [2] estimated in 2005 a pooled standard incidence ratio (SIR) for CRC of 1.9 (95 confidence interval [CI], 1.4-2.5) [4]. In another meta-analysis published 8 years later, Lutgens et al. [5] found an SIR of 1.7 (95\% CI, 1.2-2.2) and identified patients with extensive colitis and a diagnosis before age 30 years at increased risk (SIR 6.4, 95\% CI, 2.4-17.5 and 7.2, 95\% CI, 2.9-17.8, respectively). PSC and a diagnosis before the age of 40 years present additive risk factors for CD patients [6]. Currently, inclusion in a screening and surveillance program is recommended for patients with Crohn's colitis with a somewhat arbitrary definition of an inflammatory involvement of more than one-third of the colon as determined endoscopically but not histologically [7-9].

Multiple factors additionally modify the risk for CRC in patients with inflammatory bowel diseases (IBD), as shown in Table $1[10,11]$. Strictures, lead pipe colon, and pseudopolyps, which are the cumulative result of inflammation, are considered structural risk factors. However, pseudopolyps probably do not represent per se a risk factor for colonic neoplasia, including $\mathrm{CRC}$, as shown recently in a large, international, retrospective cohort study as well as prospective surveillance cohort with 22 years of

Chemoprevention in Inflammatory Bowel Disease follow-up $[12,13]$. In both studies, pseudopolyps were not independently associated with the risk of neoplasia after correction for colonic inflammation. A recent systematic review and meta-analysis pooling 164 studies analyzed 31 potential risk factors for advanced colorectal neoplasia [14]. Evidence for each factor derived from the included studies was graded as strong, moderate, or weak according to the cumulative odds or hazard ratio, the statistical significance level of the pooled studies, and the heterogeneity and number of studies analyzing the factor. Thus, despite higher odds or hazard rations, the quality of evidence for singular risk factors was often downgraded due to significant heterogeneity between the included studies or a smaller number of studies in the pooled analyses. Accordingly, the quality of evidence for extensive disease as a risk factor for CRC was classified as strong. In contrast, lowgrade dysplasia, strictures, primary sclerosing cholangitis, postinflammatory polyps, family history of CRC, and UC versus $C D$ were considered as moderate-quality evidence. Evidence for being a CRC risk factor was classified as weak for histologic inflammation, any dysplasia, colon segment resection, aneuploidy, male sex, and age.

Given the elevated risk of CRC in UC and CD with colonic involvement of $>30 \%$, the potential of medical CRC chemoprevention aside from regular surveillance colonoscopies has been debated in the past 3 decades [11]. The potential chemoprevention mechanisms by 5 -ASA are reported in numerous in vitro and a few in vivo animal studies (reviewed in [15-17]). 5-ASA interferes with diverse biochemical pathways, including the arachidonic acid metabolism pathway and TNFa, TGF-beta, NF-kappa $\mathrm{B}$, and WNT/beta-catenin pathways, all associated with the development of neoplasia [18].5-ASA also interferes with cell cycle progression on different levels, induces apoptosis in neoplastic cells, and acts as a scavenger of reactive nitrogen and oxygen metabolites $[15,16]$. Interestingly just recently, a study comparing the chemopreventive efficacy of low-dose aspirin $(100 \mathrm{mg} /$ day $)$ with 5 -ASA ( $2 \mathrm{~g} /$ day) in high-risk familial adenomatous polyposis patients without previous colectomy showed in contrast to low-dose aspirin no preventive effect of 5-ASA for recurrent polyp formation $>50 \mathrm{~mm}$ [19].

\section{5-ASA and Chemopreventive Effects in IBD - Clinical Studies}

Since 2005, 7 meta-analyses have been published, analyzing the potential chemopreventive effect of 5-ASA on the occurrence of CRC or colorectal dysplasia in patients 
Table 1. Risk factors for CRC in IBD colitis (adapted from [11])

\begin{tabular}{|c|c|}
\hline Disease-related factor & Patient-related factors \\
\hline Extensive colitis & Prior history of dysplasia \\
\hline Duration of disease & Family history of CRC in FDR, especially if $<50$ years old \\
\hline Severity of inflammation & Primary sclerosing cholangitis \\
\hline Cumulative inflammatory burden & Possible: earlier age of disease onset, male sex, and \\
\hline Structural alterations as a consequence of chronic inflammation & patient compliance with medication/follow-up \\
\hline \multicolumn{2}{|l|}{ Pseudopolyps* } \\
\hline \multicolumn{2}{|l|}{ Stricture } \\
\hline Shortened lead pipe colon & \\
\hline
\end{tabular}

Table 2. Meta-analyses: use of 5-aminosalicylates and risk of colorectal neoplasia in patients with inflammatory bowel disease

\begin{tabular}{|c|c|c|c|c|c|}
\hline $\begin{array}{l}\text { Author } \\
\text { meta-analysis }\end{array}$ & $\begin{array}{l}\text { Studies, } n \\
\text { Total (hospital-based/ } \\
\text { population-based) }\end{array}$ & $\begin{array}{l}\text { Total } \\
\text { cases }\end{array}$ & $\begin{array}{l}\text { CRC } \\
\text { cases }\end{array}$ & $\begin{array}{l}\text { Dysplasia } \\
\text { cases }\end{array}$ & Colonic neoplasia risk and 5-ASA exposure and other findings \\
\hline Nguyen et al. [21] & $13(9 / 4)$ & 1,259 & $\mathrm{Nr}$ & $\mathrm{Nr}$ & $\begin{array}{l}\text { CRC/Dys population based: } \mathrm{OR}=0.95 ; 95 \% \mathrm{Cl} 0.66-1.38 \\
\text { CRC/Dys hospital based: } \mathrm{OR}=0.58 ; 95 \% \mathrm{Cl} 0.45-0.75\end{array}$ \\
\hline O'Connor et al. [23] & $8(4 / 4)$ & 867 & 724 & 143 & $\begin{array}{l}\text { CRC/Dys: } \mathrm{OR}=0.6 ; 95 \% \mathrm{Cl} 0.4-0.9 \\
\text { Significant reduction in the hospital based but not in the population-based studies } \\
\text { No protective effect of sulfasalazine }\end{array}$ \\
\hline Bonovas et al. [24] & $31(19 / 12)$ & 2,137 & $\mathrm{Nr}$ & $\mathrm{Nr}$ & $\begin{array}{l}\text { CRC/Dys: RR: } 0.57,95 \% \mathrm{Cl} 0.45-0.71 \\
\text { Significant reduction in the hospital - and population-based studies } \\
\text { Significant reduction for both CRC and dysplasia } \\
\text { No effect of 5-ASA on CDCRC prevention } \\
\text { 5-ASA dose effect }>1.2 \mathrm{~g} / \mathrm{d} \text {, sulfasalazine not effective }\end{array}$ \\
\hline Zeng et al. [26] & $5(5 / 0)$ & 776 & - & 776 & $\begin{array}{l}\text { (This meta-analysis analyzed progression from LGD to HGD/CRC only). } \\
\text { Progression to CRC/HGD: } \mathrm{HR}=0.91,95 \% \mathrm{CI} 0.55-1.51 \\
\text { No significance by concomitant PSC status, study quality, sample size, or IBD } \\
\text { type }\end{array}$ \\
\hline
\end{tabular}

Italics: additional significant findings. Nr, not reported; CRC, colorectal cancer; CD, Crohn's disease, Dys, dysplasia; HGD, high-grade dysplasia; UC, ulcerative colitis; Cl, confidence interval; 5-ASA, 5-aminosalicylic acid; CD, Crohn's disease.

with IBD (Table 2) [20-26]. The number of studies included in the individual meta-analyses varied mainly due to the increasing number of original articles on this topic. In general, the studies included in the meta-analyses can be separated according to study setting in population- based and clinical cohorts, which have a smaller sample size than population-based studies and are vulnerable to selection bias and have uncertain generalizability. Thus, it is interesting that in most meta-analyses, populationbased studies show no or only a marginal CRC protective 
Table 3. Meta-analyses: use of thiopurines and risk of colorectal neoplasia in patients with inflammatory bowel disease

\begin{tabular}{|c|c|c|c|c|c|}
\hline $\begin{array}{l}\text { Author meta- } \\
\text { analysis }\end{array}$ & $\begin{array}{l}\text { Studies, } n \\
\text { Total (hospital- } \\
\text { based/ } \\
\text { population- } \\
\text { based) }\end{array}$ & $\begin{array}{l}\text { Total } \\
\text { cases }\end{array}$ & CRC cases & $\begin{array}{l}\text { Dysplasia } \\
\text { cases }\end{array}$ & Colonic neoplasia risk \\
\hline Gong et al. [32] & 19 & $\mathrm{Nr}$ & $\mathrm{Nr}$ & $\mathrm{Nr}$ & $\begin{array}{l}\mathrm{RR}=0.71,95 \% \mathrm{Cl} 0.54-0.94 \text {, result significant for heterogeneity } \\
\text { Analysis separated by case-control }(\mathrm{RR}=0.46,95 \% \mathrm{Cl} 0.29-0.74 \text {, result } \\
\text { significant for heterogeneity) and cohort study }(\mathrm{RR}=0.96,95 \% \mathrm{Cl} 0.94- \\
0.98)\end{array}$ \\
\hline Jess et al. [33] & 15 & 1,574 & $\begin{array}{l}1,344230 \mathrm{CRC} / \\
\text { high- or low-grade Dys }\end{array}$ & $\mathrm{Nr}$ & $\begin{array}{l}\mathrm{OR}=0.87,95 \% \mathrm{Cl} 0.59-1.29 \text { (but significant heterogeneity) } \\
\text { In subgroup analysis separation in clinical based }(n=13 ;[\mathrm{OR}=0.87,95 \% \mathrm{Cl} \\
0.59-1.09]) \text {, case-control }(n=8 ; \mathrm{OR}=0.83,95 \% \mathrm{Cl} 0.65-1.08 \text {, and cohort } \\
\text { study }(n=7 ; \mathrm{OR}=0.93,95 \% \mathrm{Cl} 0.67-1.28)\end{array}$ \\
\hline Lu et al. [34] & 24 & 8,698 & $\begin{array}{l}6,954 \text { CRC } 1,744 \\
\text { (CRC and/or } \\
\text { high-grade Dys) }\end{array}$ & $\mathrm{Nr}$ & $\begin{array}{l}\mathrm{OR}=0.63,95 \% \mathrm{Cl} 0.46-0.86 \\
\text { Colonic neoplasia risk decreases significant for } \mathrm{UC}(\mathrm{OR}=0.67,95 \% \mathrm{Cl} \\
0.45-0.98) \text {, but not for } \mathrm{CD} \text { patients }(\mathrm{OR}=1.06,95 \% \mathrm{Cl} 0.54-2.09) \\
\text { Decrease of risk significant for } \mathrm{CRC}(\mathrm{OR}=0.65,95 \% \mathrm{Cl} 0.45-0.96) \text { and } \\
\text { advanced colorectal neoplasia ( } \mathrm{CRC} \text { and } / \text { or high-grade } \mathrm{Dys})(\mathrm{OR}=0.62 \text {, } \\
95 \% \mathrm{Cl} 0.44-0.89) \text {, but not dysplasia alone }(\mathrm{OR}=0.90,95 \% \mathrm{Cl} 0.37-2.21) \\
\text { Protective effect of thiopurines distinct in clinic based }(\mathrm{OR}=0.59,95 \% \mathrm{Cl} \\
0.42-0.82) \text { and case-control studies }(\mathrm{OR}=0.40,95 \% \mathrm{Cl} 0.26-0.62), \text { but not } \\
\text { in population-based studies ( } \mathrm{OR}=0.95,95 \% \mathrm{Cl} 0.55-1.62) \text { and cohort } \\
\text { studies }(\mathrm{OR}=0.98,95 \% \mathrm{Cl} 0.81-1.18)\end{array}$ \\
\hline Zhu et al. [35] & 27 & $\mathrm{Nr}$ & $\mathrm{Nr}$ & $\mathrm{Nr}$ & $\begin{array}{l}\text { Analyses separated by case-control }(\mathrm{OR}=0.49,95 \% \mathrm{Cl} 0.34-0.70 \text {, result } \\
\text { significant for heterogeneity) and cohort study }(\mathrm{OR}=0.96,95 \% \mathrm{Cl} 0.94- \\
0.98) \\
\text { In subgroup analysis separation in hospital based }(n=12 ; \mathrm{OR}=0.37,95 \% \\
\mathrm{Cl} 0.26-0.52) \text { and population based ( } n=4 ; \mathrm{OR}=0.80,95 \% \mathrm{Cl} 0.58-1.12) \text {, } \\
\text { results significant for heterogeneity }\end{array}$ \\
\hline Zeng et al. [26] & $5(5 / 0)$ & 776 & - & 776 & $\begin{array}{l}\text { (This meta-analysis analyzed progression from LGD to } \mathrm{HGD} / \mathrm{CRC} \text { only). } \\
\text { Progression to CRC/HGD: } \mathrm{HR}=0.64,95 \% \mathrm{Cl} 0.23-1.79 \\
\text { No significance by concomitant PSC status, study quality, sample size, or } \\
\text { IBD type }\end{array}$ \\
\hline
\end{tabular}

$\mathrm{Nr}$, not reported; $\mathrm{CRC}$, colorectal cancer, Dys, dysplasia; $\mathrm{HGD}$, high-grade dysplasia; Cl, confidence interval; IBD, inflammatory bowel disease; CD, Crohn's disease.

effect of 5-ASA in contrast to a robust effectiveness of clinical-based studies. This difference may reflect a selection bias of the clinically based studies favoring a higher risk patient group. Only the most recent and most comprehensive meta-analysis by Bonovas reports for the first time a CRC protective effect of 5-ASA for both the clinical-based (RR: $0.46,95 \%$ CI $0.34-0.61$ ) and populationbased (RR: 0.70, 95\% CI 0.52-0.94) studies. Bonovas et al. [24] included 17 studies with UC patients, 2 studies with CD only, and 12 studies included both UC and CD patients. The reduction of colorectal neoplasia with 5-ASA was only significant in patients with UC but not in patients with $\mathrm{CD}$. Also, based on the available data, a dose effect of 5-ASA exists. 5-ASA doses $>1.2 \mathrm{~g}$ /day have a more profound effect than $<1.2 \mathrm{~g} /$ day $[22,24,25]$. There is some inconsistency regarding sulfasalazine, which even at doses $>2 \mathrm{~g} /$ day seemed to have no significant impact on CRC prevention [22-25]. However, one has to keep in mind that the recommended maintenance dose of sulfasalazine $2 \mathrm{~g}$ /day is equal to only $800 \mathrm{mg} 5$-ASA daily, which is below the effective dose of mesalamine of $1.2 \mathrm{~g}$ to prevent CRC [27]. Despite the overall consistent findings of the protective effects of 5-ASA in the meta-analyses, there are limitations for the interpretation of the results due to different design and methodology of the individual studies, the definitions of the length of 5-ASA exposure, and different degrees of control of confounding. Also, as Bonovas et al. [24] point out, a "small study effect" for the clinical-based studies may be present. A small study effect exists if smaller studies show larger treatment effects than large ones, which is clearly the case for the available 5-ASA studies. No study has yet shown 
a beneficial chemopreventive effect of 5-ASA in combination, for example, with anti-TNF agents, which would combine both the anti-inflammatory effects of both agents with the additional benefits of the proposed molecular mechanisms for CRC prevention of 5-ASA. However, if one considers only clinical outcomes, 5-ASA seems to have no added benefit to anti-TNF therapy in patients with UC, but in the available studies, CRC incidences are not reported [28-30].

To ultimately define the role of 5-ASA for chemoprevention in patients with IBD, a prospective, double-blinded placebo-controlled trial would be required. However, such a trial would pose several obstacles, making it very unlikely that it will ever occur. Assuming a 2\% cumulative incidence of CRC, a minimum of 5,260 UC patients would be needed, with a follow-up time of 10 years [31]. Besides problems with compliance and dropouts, this trial would also be ethically rather challenging to implement if run as a 5-ASA monotherapy trial since a standard therapy for UC would be withheld in the placebo arm. In the setting of a 5-ASA or placebo add-on therapy trial, for example, in combination with biologics, it would be difficult to control for confounders.

\section{Chemoprevention Biologics and Small Molecules (Thiopurines, JAK Inhibitors)}

So far, no data are available for chemoprevention with biologics (anti-TNF, anti-IL-12/IL-23, or anti-integrin agents) or newer small-molecule therapies such as Janus kinase (JAK) inhibitors. For none of these agents, specific molecular mechanisms are known, which would interfere with carcinogenesis aside from controlling intestinal inflammation.

Five meta-analyses compiled the results of several studies investigating the chemopreventive effect of thiopurines (Table 3) [26, 32-35]. In contrast to 5-ASA, thiopurines have no known molecular mechanism to block tumorigenesis. The risk of CRC is most likely decreased solely by controlling chronic colonic inflammation, which, aside from genetic predisposition and coexisting PSC, appears to be one of the main drivers for CRC pathogenesis in IBD patients [36]. The initial meta-analyses for thiopurines and the risk of CRC were negative, but later meta-analyses did show a significant chemopreventive effect of thiopurines (Table 3). This change is most likely due to an increasing number of small clinical-based studies, which could indicate again to the aforementioned "small study effect." All meta-analyses report significant heterogeneity, impacting the overall interpretation of the results. Population-based studies for thiopurines are negative even if analyses were performed in subpopulations (e.g., those with longstanding colitis in the CESAME cohort) [37]. In contrast to 5-ASA studies, no dose-dependent chemopreventive effects for thiopurines have been reported since data about thiopurine dosing were unreliable and scarce.

Early data suggested a substantial chemoprevention benefit with ursodeoxycholic acid in patients with PSC $[38,39]$. However, 2 meta-analyses show heterogeneity across studies and caution that the beneficial effect if at all was only associated with low-dose ursodeoxycholic acid (8-15 $\mathrm{mg} / \mathrm{kg}$ bodyweight) $[40,41]$. Also an overall protective effect for folic acid supplementation on CRC development in patients with IBD has been reported in a meta-analysis of 10 studies with 4,517 patients. The pooled hazard ratio was 0.58 (95\% CI, $0.37-0.80)$, but there was a low-moderate heterogeneity among the studies.

\section{What Are the Current Guideline Recommendations for Chemoprevention?}

The current American, British, and European recommendations for chemoprevention in patients with UC are outlined in Table 4 [42-45]. A specific recommendation in regard to chemoprevention for CD patients does not exist. The recent British Society of Gastroenterology Consensus recommends the chemoprevention with 5-ASA [43]. The guideline does not recommend the use of thiopurines, despite a positive meta-analysis showing a protective effect of thiopurines in patients with UC (but not for $\mathrm{CD}$ ) since "potential benefit in reducing CRC risk must be weighed against the increase in the risk of lymphoma (with thiopurine therapy), particularly in older patients" [34]. The British guidelines also point out the missing data for methotrexate, calcineurin inhibitors, anti-TNF, and anti-integrin agents. The European Crohn's and Colitis Organization (ECCO) states that 5-ASA may reduce the incidence of CRC but does not give firm recommendations to stop or continue 5-ASA, for example, in the setting of concomitant therapies with biologics [42]. At the time of establishing this guideline, there was still insufficient evidence for the recommendation of thiopurines. The more recent American College of Gastroenterology (ACG) recommendations are embedded in a broader context [44]. In a so-defined key concept (key concepts or statements were based on the extrapolation 
Table 4. Guideline recommendation for chemoprevention in IBD

\begin{tabular}{ll}
\hline Guideline/publication date & Recommendation \\
\hline Magro et al. [42] ECCO 2017 & $\begin{array}{l}\text { "Chemoprevention with mesalamine compounds may reduce the incidence of colorectal cancer in } \\
\text { ulcerative colitis. There is insufficient evidence to recommend for or against chemoprevention } \\
\text { with thiopurines" }\end{array}$ \\
\hline
\end{tabular}

Rubin et al. [44] American College of "No medical therapy has demonstrated sufficient prevention of dysplasia or CRC to avoid Gastroenterology 2019 colonoscopic surveillance in UC." (Key concept statement)

Lamb et al. [43] British Society of

Gastroenterology Consensus 2019

"We recommend that patients with ulcerative colitis or IBD-U with left-sided or more extensive
disease should be advised to take mesalazine in doses of at least $2 \mathrm{~g}$ daily to reduce risk of
colorectal cancer." We suggest that thiopurines may reduce the risk of colorectal cancer in patients
with ulcerative colitis and IBD-U, but evidence for a chemopreventive role from methotrexate,
calcineurin inhibitors, anti-TNF, and anti-integrin agents is lacking at present and they cannot be
currently recommended solely for chemoprevention against colorectal cancer (GRADE: weak
recommendation, low-quality evidence. Agreement: 93\%)

Singh et al. [45] American

"In adult outpatients with moderate to severe UC, who have failed 5-ASAs, and have escalated to

Gastroenterology Association 2020 therapy with biologic agents, tofacitinib, and/or immunomodulators, there may be no benefit to continuing 5-ASAs over stopping 5-ASAs"

5-ASA, 5-aminosalicylic acid; IBD, inflammatory bowel disease.

of evidence or an expert opinion and were not amenable to a defined Grading of Recommendations Assessment, Development, and Evaluation [GRADE] process, either because of the structure of the statement or because of the available evidence), Rubin et al. [46] state "Because the primary driver of cancer risk in UC seems to be inflammation, there may be a role for primary prevention (chemoprevention) of CRC by medical treatment of UC. Data from various case-control and cohort studies have demonstrated a protective effect of medical therapies for developing dysplasia in UC, including 5-ASA therapies [25] and azathioprine [35]. However, these results have been inconsistent across studies, and effect sizes are less when adjustments for all confounders, including the degree of inflammation, are included in the analyses [46]. Therefore, optimized medical therapy alone is not an appropriate prevention method for CRC in patients with UC and does not supplant colonoscopy. Using appropriate secondary prevention (screening and surveillance) is necessary at this time to prevent CRC in patients with longstanding UC." The latest 2020 American Gastroenterology Association (AGA) guideline for moderate to severe colitis focuses exclusively on medical treatment and not on chemoprevention [45]. But in the context of the question, if 5-ASA should be continued besides other therapies such as biologics or JAK inhibitors after 5-ASA failure, Singh et al. [45] discuss the following: "While large observational studies and meta-analyses have variably

Chemoprevention in Inflammatory Bowel Disease suggested that UC patients treated with 5-ASA have a lower risk of developing colorectal cancer, recent evidence suggests that chronically active disease is a decisive risk factor for developing neoplasia, and sustained remission is a protective factor against colorectal cancer regardless of therapy used that achieves this outcome" [47].

\section{5-ASA Chemoprophylaxis in IBD: Is It Necessary in the Age of Biologics and Small Molecules?}

As stated by Ullman and Itzkowitz [36], colonic inflammation is most likely one of the main drivers of CRC in both UC and CD. If uncontrolled inflammation is the leading cause of CRC in patients with IBD, suppressing inflammation should lower the risk of colitis-associated cancer. This cause-effect relationship is suggested by the recent meta-analyses of thiopurines' effectiveness in UC, since thiopurines have no known direct inhibitory effect on the molecular CRC pathway but only downregulate inflammation-associated genes [34, 35]. Thus, most likely biologics or small molecules, which successfully treat colonic inflammation in $\mathrm{UC}$ or $\mathrm{CD}$, are also protective for the development of CRC solely by blocking inflammatory pathways. Overall, given the current knowledge regarding the chemoprevention of CRC in IBD, the optimal therapy is the same as the recommended treatment goals to achieve clinical remission and resolution or improve- 
ment of mucosal inflammation. The timing and possibility of achieving optimal outcomes vary across individual patients and therapies [48].

Overall, the current data suggest that in patients with 5-ASA monotherapy, 5-ASA continuation is mandatory to maintain clinical remission. There may be also a chemopreventive beneficial effect, but to separate this effect from the control of inflammation is difficult. If patients are on other more advanced therapies such as biologics or JAK inhibitors and achieve deep remission (clinical remission + mucosal healing), an addition of 5-ASA is according to the current state of knowledge not meaningful. An "extra" chemopreventive effect on top of the recommended endoscopic surveillance is most likely negligible. However, studies in the CRC/IBD high-risk groups with CRC family history or PSC would be interesting and could shed light on the question of an additional chemopreventive effect of such a 5-ASA combination therapy.

\section{Conflict of Interest Statement}

Hans Herfarth has received consulting fees from Allakos, Alivio, AMAG, Boehringer Ingelheim, Finch, Gilead, Janssen, Otsuka, Pfizer, Seres research support from Allakos, Artizan, and Pfizer. Stephan R. Vavricka has received consulting fees, speakers' honorary, and unrestricted research grants from Abbott, Alfasigma, Amgen, Arenapharm, Falk Pharma GmbH, Ferring Pharmaceuticals, Gilead, iQuone, Janssen, MSD, Permamed, Pfizer Inc., Sanofi-Aventis, Takeda, Tillotts, UCB, and Vifor.

\section{Funding Sources}

None.

\section{Author Contributions}

H.H. performed data collection, reviewed and analyzed the data, and drafted, revised, and approved the final manuscript. S.V. performed data collection, reviewed and analyzed the data, and revised and approved the final manuscript.

\section{References}

1 Eaden JA, Abrams KR, Mayberry JF. The risk of colorectal cancer in ulcerative colitis: a meta-analysis. Gut. 2001 Apr;48(4):526-35.

2 Jess T, Horváth-Puhó E, Fallingborg J, Rasmussen HH, Jacobsen BA. Cancer risk in inflammatory bowel disease according to patient phenotype and treatment: a Danish population-based cohort study. Am J Gastroenterol. 2013 Dec;108(12):1869-76.

3 Olen O, Erichsen R, Sachs MC, Pedersen L, Halfvarson J, Askling J, et al. Colorectal cancer in ulcerative colitis: a Scandinavian population-based cohort study. Lancet. 2020 Jan 11;395(10218):123-31.

4 Jess T, Gamborg M, Matzen P, Munkholm P, Sørensen TI. Increased risk of intestinal cancer in Crohn's disease: a meta-analysis of population-based cohort studies. Am J Gastroenterol. 2005 Dec;100(12):2724-9.

5 Lutgens MW, van Oijen MG, van der Heijden GJ, Vleggaar FP, Siersema PD, Oldenburg B. Declining risk of colorectal cancer in inflammatory bowel disease: an updated meta-analysis of population-based cohort studies. Inflamm Bowel Dis. 2013 Mar-Apr;19(4):789-99.

6 Olen O, Erichsen R, Sachs MC, Pedersen L, Halfvarson J, Askling J, et al. Colorectal cancer in Crohn's disease: a Scandinavian population-based cohort study. Lancet Gastroenterol Hepatol. 2020 May;5(5):475-84.

7 Itzkowitz SH, Present DH. Crohn's, colitis foundation of America colon cancer in IBDSG. Consensus conference: colorectal cancer screening and surveillance in inflammatory bowel disease. Inflamm Bowel Dis. 2005 Mar;11(3):314-21.
8 Lichtenstein GR, Loftus EV, Isaacs KL, Regueiro MD, Gerson LB, Sands BE. ACG clinical guideline: management of Crohn's disease in adults. Am J Gastroenterol. 2018 Apr;113(4): 481-517.

9 Maaser C, Sturm A, Vavricka SR, Kucharzik $\mathrm{T}$, Fiorino G, Annese V, et al. ECCO-ESGAR guideline for diagnostic assessment in ibd part 1: initial diagnosis, monitoring of known IBD, detection of complications. J Crohns Colitis. 2019 Feb 1;13(2):144-64.

10 Farraye FA, Odze RD, Eaden J, Itzkowitz SH AGA technical review on the diagnosis and management of colorectal neoplasia in inflammatory bowel disease. Gastroenterology. 2010 Feb;138(2):746-74

11 Shah SC, Itzkowitz SH. Reappraising risk factors for inflammatory bowel disease-associated neoplasia: implications for colonoscopic surveillance in IBD. J Crohns Colitis. 2020 Sep 7;14(8):1172-7

12 Mahmoud R, Shah SC, Ten Hove JR, Torres J, Mooiweer E, Castaneda D, et al. No association between pseudopolyps and colorectal neoplasia in patients with inflammatory bowel diseases. Gastroenterology. 2019 Apr; 156(5):1333-e3.

13 de Jong ME, Gillis VELM, Derikx LAAP, Hoentjen F. No increased risk of colorectal neoplasia in patients with inflammatory bowel disease and postinflammatory polyps. Inflamm Bowel Dis. 2020 Aug 20;26(9):1383-9.
14 Wijnands AM, de Jong ME, Lutgens MWMD, Hoentjen F, Elias SG, Oldenburg B, et al. Prognostic factors for advanced colorectal neoplasia in inflammatory bowel disease: systematic review and meta-analysis. Gastroenterology. 2021 Apr;160(5):1584-98.

15 Stolfi C, Pellegrini R, Franze E, Pallone F, Monteleone G. Molecular basis of the potential of mesalazine to prevent colorectal cancer. World J Gastroenterol. 2008 Jul 28;14(28): 4434-9.

16 Lyakhovich A, Gasche C. Systematic review: molecular chemoprevention of colorectal malignancy by mesalazine. Aliment Pharmacol Ther. 2010 Jan 15;31(2):202-9.

17 Lang M, Gasche C. Chemoprevention of colorectal cancer. Dig Dis. 2015;33(1):58-67.

18 Bajpai M, Seril DN, Van Gurp J, Geng X, Alvarez J, Minacapelli CD, et al. Effect of longterm mesalamine therapy on cancer-associated gene expression in colonic mucosa of patients with ulcerative colitis. Dig Dis Sci. 2019 Mar;64(3):740-50.

19 Ishikawa H, Mutoh M, Sato Y, Doyama H, Tajika M, Tanaka $S$, et al. Chemoprevention with low-dose aspirin, mesalazine, or both in patients with familial adenomatous polyposis without previous colectomy (J-FAPP Study IV): a multicentre, double-blind, randomised, two-by-two factorial design trial. Lancet Gastroenterol Hepatol. 2021;6(6):474-81.

20 Velayos FS, Terdiman JP, Walsh JM. Effect of 5 -aminosalicylate use on colorectal cancer and dysplasia risk: a systematic review and metaanalysis of observational studies. Am J Gastroenterol. 2005 Jun;100(6):1345-53. 
21 Nguyen GC, Gulamhusein A, Bernstein CN. 5 -aminosalicylic acid is not protective against colorectal cancer in inflammatory bowel disease: a meta-analysis of non-referral populations. Am J Gastroenterol. 2012 Sep;107(9): 1298-305.

22 Zhao LN, Li JY, Yu T, Chen GC, Yuan YH, Chen QK. 5-aminosalicylates reduce the risk of colorectal neoplasia in patients with ulcerative colitis: an updated meta-analysis. PLoS One. 2014;9(4):e94208.

23 O'Connor A, Packey CD, Akbari M, Moss AC. Mesalamine, but not sulfasalazine, reduces the risk of colorectal neoplasia in patients with inflammatory bowel disease: an agentspecific systematic review and meta-analysis. Inflamm Bowel Dis. 2015 Nov;21(11):25629.

24 Bonovas S, Fiorino G, Lytras T, Nikolopoulos G, Peyrin-Biroulet L, Danese S. Systematic review with meta-analysis: use of 5-aminosalicylates and risk of colorectal neoplasia in patients with inflammatory bowel disease. Aliment Pharmacol Ther. 2017 May;45(9): 1179-92.

25 Qiu X, Ma J, Wang K, Zhang H. Chemopreventive effects of 5-aminosalicylic acid on inflammatory bowel disease-associated colorectal cancer and dysplasia: a systematic review with meta-analysis. Oncotarget. 2017 Jan 3; 8(1):1031-45

26 Zeng J, Meng ZM, Huang XL, Gan HT. Effects of 5 -aminosalicylates or thiopurines on the progression of low-grade dysplasia in patients with inflammatory bowel disease: a systematic review and meta-analysis. Int J Colorectal Dis. 2021 Jan;36(1):11-8.

27 Hanauer SB, Stathopoulos G. Risk-benefit assessment of drugs used in the treatment of inflammatory bowel disease. Drug Saf. 1991 May-Jun;6(3):192-219.

28 Singh S, Proudfoot JA, Dulai PS, Jairath V, Fumery M, Xu R, et al. No benefit of concomitant 5-aminosalicylates in patients with ulcerative colitis escalated to biologic therapy: pooled analysis of individual participant data from clinical trials. Am J Gastroenterol. 2018 Aug;113(8):1197-205.

29 Ungaro RC, Limketkai BN, Jensen CB, Allin KH, Agrawal M, Ullman T, et al. Stopping 5 -aminosalicylates in patients with ulcerative colitis starting biologic therapy does not increase the risk of adverse clinical outcomes: analysis of two nationwide population-based cohorts. Gut. 2019 Jun;68(6):977-84.
30 Singh S, Kim J, Zhu W, Dulai PS, Sandborn WJ, Jairath V. No benefit of continuing versus stopping 5-aminosalicylates in patients with ulcerative colitis escalated to anti-metabolite therapy. Aliment Pharmacol Ther. 2020 Aug; 52(3):481-91.

31 Rubin DT, Lashner BA. Will a 5-ASA a day keep the cancer (and dysplasia) away? Am J Gastroenterol. 2005 Jun;100(6):1354-6.

32 Gong J, Zhu L, Guo Z, Li Y, Zhu W, Li N, et al. Use of thiopurines and risk of colorectal neoplasia in patients with inflammatory bowel diseases: a meta-analysis. PLoS One. 2013; 8(11):e81487.

33 Jess T, Lopez A, Andersson M, Beaugerie L, Peyrin-Biroulet L. Thiopurines and risk of colorectal neoplasia in patients with inflammatory bowel disease: a meta-analysis. Clin Gastroenterol Hepatol. 2014 Nov;12(11): 1793-e1.

34 Lu MJ, Qiu XY, Mao XQ, Li XT, Zhang HJ Systematic review with meta-analysis: thiopurines decrease the risk of colorectal neoplasia in patients with inflammatory bowel disease. Aliment Pharmacol Ther. 2018 Feb; 47(3):318-31.

35 Zhu Z, Mei Z, Guo Y, Wang G, Wu T, Cui X, et al. Reduced risk of inflammatory bowel disease-associated colorectal neoplasia with use of thiopurines: a systematic review and metaanalysis. J Crohns Colitis. 2018 Apr 27;12(5): 546-58.

36 Ullman TA, Itzkowitz SH. Intestinal inflammation and cancer. Gastroenterology. 2011 May;140(6):1807-16.

37 Carrat F, Seksik P, Colombel JF, Peyrin-Biroulet L, Beaugerie L, Group CS. The effects of aminosalicylates or thiopurines on the risk of colorectal cancer in inflammatory bowel disease. Aliment Pharmacol Ther. 2017 Feb; 45(4):533-41.

38 Tung BY, Emond MJ, Haggitt RC, Bronner MP, Kimmey MB, Kowdley KV, et al. Ursodiol use is associated with lower prevalence of colonic neoplasia in patients with ulcerative colitis and primary sclerosing cholangitis. Ann Intern Med. 2001;134(2):89-95.

39 Pardi DS, Loftus EV Jr, Kremers WK, Keach J, Lindor KD. Ursodeoxycholic acid as a chemopreventive agent in patients with ulcerative colitis and primary sclerosing cholangitis. Gastroenterology. 2003 Apr;124(4):88993.
40 Hansen JD, Kumar S, Lo WK, Poulsen DM, Halai UA, Tater KC. Ursodiol and colorectal cancer or dysplasia risk in primary sclerosing cholangitis and inflammatory bowel disease: a meta-analysis. Dig Dis Sci. 2013 Nov;58(11): 3079-87.

41 Singh S, Khanna S, Pardi DS, Loftus EV Jr, Talwalkar JA. Effect of ursodeoxycholic acid use on the risk of colorectal neoplasia in patients with primary sclerosing cholangitis and inflammatory bowel disease: a systematic review and meta-analysis. Inflamm Bowel Dis. 2013 Jul;19(8):1631-8.

42 Magro F, Gionchetti P, Eliakim R, Ardizzone S, Armuzzi A, Barreiro-de Acosta M, et al. Third European evidence-based consensus on diagnosis and management of ulcerative colitis. Part 1: definitions, diagnosis, extra-intestinal manifestations, pregnancy, cancer surveillance, surgery, and ileo-anal pouch disorders. J Crohns Colitis. 2017 Jun 1;11(6): 649-70.

43 Lamb CA, Kennedy NA, Raine T, Hendy PA, Smith PJ, Limdi JK, et al. British Society of Gastroenterology consensus guidelines on the management of inflammatory bowel disease in adults. Gut. 2019 Dec;68(Suppl 3):s106.

44 Rubin DT, Ananthakrishnan AN, Siegel CA, Sauer BG, Long MD. ACG clinical guideline: ulcerative colitis in adults. Am J Gastroenterol. 2019 Mar;114(3):384-413.

45 Singh S, Allegretti JR, Siddique SM, Terdiman JP. AGA technical review on the management of moderate to severe ulcerative colitis. Gastroenterology. 2020 Apr;158(5):1465-96 e17.

46 Rubin DT, Huo D, Kinnucan JA, Sedrak MS, McCullom NE, Bunnag AP, et al. Inflammation is an independent risk factor for colonic neoplasia in patients with ulcerative colitis: a case-control study. Clin Gastroenterol Hepatol. 2013 Dec;11(12):1601-8 e14.

47 Dulai PS, Sandborn WJ, Gupta S. Colorectal cancer and dysplasia in inflammatory bowel disease: a review of disease epidemiology, pathophysiology, and management. Cancer Prev Res. 2016 Dec;9(12):887-94.

48 Turner D, Ricciuto A, Lewis A, D’Amico F, Dhaliwal J, Griffiths AM, et al. STRIDE-II: an update on the selecting therapeutic targets in inflammatory bowel disease (stride) initiative of the international organization for the study of ibd (ioibd): determining therapeutic goals for treat-to-target strategies in ibd. Gastroenterology. $2021 \mathrm{Apr} ; 160(5): 1570-83$. 